\title{
Construction of light-harvesting reverse micelles in
}

\section{nanoscopic dimensions}

\author{
Masaki Takahashi, ${ }^{a,}{ }^{*}$ Yasunori Ichihashi ${ }^{a}$ Natsuko Nishizawa, ${ }^{a}$ Shuhei Ohno, ${ }^{a}$ Norifumi Fujita ${ }^{\circ},{ }^{b}$ \\ Mitsuji Yamashita, ${ }^{a}$ Tetsuya Sengoku ${ }^{a}$ and Hidemi Yoda, ${ }^{a, *}$
}

\begin{abstract}
${ }^{a}$ Department of Materials Science, Faculty of Engineering, Shizuoka University, 3-5-1 Johoku, Nakaku, Hamamatsu, Shizuoka 432-8561, Japan

${ }^{b}$ Department of Chemistry and Biochemistry, Graduate School of Engineering, Kyushu University, 744 Moto-oka, Nishi-ku, Fukuoka 819-0395, Japan
\end{abstract}

†Present address: Department of Chemistry and Biotechnology School of Engineering, The University of Tokyo, 7-3-1 Hongo, Bunkyo-ku, Tokyo 113-8656, Japan.

Tel: +81-53-478-1621; FAX: +81-53-478-1621; e-mail address: tmtakah@ipc.shizuoka.ac.jp Tel: +81-53-478-1150; FAX: +81-53-478-1150; e-mail address: tchyoda@ipc.shizuoka.ac.jp 
Keywords: anthracene; perylene; light-harvesting reverse micelle

Abstract: Construction of light-harvesting reverse micelle system was achieved in nanoscopic dimensions via self-assembly of anthracene-perylene triad which could undergo efficient intramolecular energy transfer from the anthracene antennae to the perylene cores. Absorption spectra of the reverse micelles in toluene solutions exhibited broad, unstructured, and red-shifted bands attributed to interacting chromophores within molecular aggregates, while the emission spectra showed significant fluorescence quenching of both the excited anthracene and the perylene groups. The atomic force microscope (AFM) analysis revealed a number of small and medium-sized spherical objects that can be attributed to the individual reverse micelles and their assemblies. A cross-sectional view of the AFM image indicated that nearly $90 \%$ of these peak heights were less than $10 \mathrm{~nm}$. Titration experiments of fluorescence properties of the reverse micelles allowed determination of its cmc value as $3 \mu \mathrm{M}$. Spectroscopic and microscopic behavior of a series of the reverse micelles at the $W_{0}$ values (water/surfactant ratios) of 30,50,100, and 200 suggested that the reverse micelles should have a uniform aggregate size independent of the water/surfactant ratio, revealing a unique relation between specific geometrical configuration of the amphiphilic molecules and intrinsic size of the reverse micelles. 


\section{Introduction}

Development of efficient light-harvesting materials has been the subject of continuous interest for converting solar energy into usable energy sources. Nature has evolved effective light-harvesting systems for absorbing photons of a broad spectral range employing large number of antenna pigments held in particular three-dimensional arrays. Considering this, a considerable amount of effort has been directed towards designing and synthesizing artificial light-harvesting systems that make it possible to bring a number of chromophores together in nanoscopic spaces. ${ }^{1}$ Many of the synthetic strategies for creating these multichromophoric systems have utilized nanoscopic-sized molecular structures, complexes, or assemblies such as dendrimers,${ }^{2-4}$ polymers, ${ }^{5}$ metal complexes, ${ }^{6}$ vesicles,${ }^{7} \pi$ organogels, ${ }^{8}$ supramolecular assemblies, ${ }^{9}$ and so on. From the standpoint of molecular design, reverse micelles may offer a design basis for practical light-harvesting systems that bring many antenna elements held together in nanoscopic dimensions through self-assembly, generating free volumes within amphiphilic enclosures. In the reverse micellar arena, research attention has focused on constructing light-harvesting systems that utilized aliphatic reverse micelles as nanoscopic-sized hosts for the binding of photoactive guest units. ${ }^{10}$ The objective of our work is to construct reverse micelles for applications such as versatile scaffolds for artificial photosynthetic systems, in which amphiphilic photoactive units form lightharvesting molecular shells allowing for directed energy transfer from the periphery to the core of the globular assemblies. In the present paper, we report our initial efforts in developing the light-harvesting reverse micellar systems through self-assembly of amphiphilic anthracene-perylene triads (Scheme 1).

$<$ Insert Scheme 1 here $>$

\section{Results and Discussion}

$N, N^{\prime}$-Bis(9-anthracenylmethyl)-substituted 1,3,8,10-tetrahydro-2,9-diazadibenzo[ $\left.c d, l m\right]$ perylene 1, which can be used for preparation of the amphiphilic building block, was synthesized according to 
established literature procedures (Scheme 2). ${ }^{11}$ The reaction of 3,4,9,10-tetra(chloromethyl)perylene with 9-aminomethyl-4,5-bis(2-ethylhexyl)anthracene resulted in the formation of $\mathbf{1}$ in $73 \%$ isolated yield via nucleophilic substitution/cyclization. The structure of $\mathbf{1}$, containing two anthracene and one perylene chromophoric units, was confirmed by UV-vis spectroscopic analyses along with ${ }^{1} \mathrm{H}$ and ${ }^{13} \mathrm{C}$ NMR, IR, high-resolution mass spectral studies. The UV-vis spectrum in toluene exhibited three and two vibrational fine structures at 360,378 , and $401 \mathrm{~nm}$ and at 432 and $461 \mathrm{~nm}$ attributed to the anthracene and perylene chromophores, respectively (Fig. 1A). A remarkable feature of this trichromophoric system is that direct excitation of the anthracene chromophores leads to exclusive evolution of a fluorescence emission from the perylene chromophore. The steady-state fluorescence spectrum of 1 displayed significant emission bands with the maxima centered at 470 and $500 \mathrm{~nm}$ without appearance of the other fluorescence signals when excited at $378 \mathrm{~nm}$ (Fig. 1B). This can be taken as unambiguous evidence to suggest that there is an efficient intramolecular energy transfer from the anthracene antennae to the perylene cores since possibilities of intermolecular energy transfer should be ruled out on the basis of the experimental conditions. The relative ratio of the peaks corresponding to the anthracene donor, while normalizing for the peaks corresponding to the perylene acceptor, can be used to estimate the energy transfer efficiency (Fig. 2). ${ }^{12}$ According to this methodology, we found that the energy transfer took place almost quantitatively.

\author{
$<$ Insert Scheme 2 here $>$ \\ $<$ Insert Fig. 1 here $>$ \\ $<$ Insert Fig. 2 here $>$
}

Having elucidated the light-harvesting functionality of $\mathbf{1}$, we turned our attention to the selfassembling behavior of the amphiphilic anthracene-perylene triad in the isotropic toluene medium. Conversion of 1 to the amphiphilic building unit was conducted by protonation of the tertiary amine groups in $\mathbf{1}$. When a $0.5 \mathrm{mM}$ solution of 1 in toluene was treated with 2 molar equivalents of sulfuric 
acid diluted with water at $W_{0}$ value of $10\left(W_{0}=\left[\mathrm{H}_{2} \mathrm{O}\right] /[1]\right)$, followed by sonication for $3 \mathrm{~min}$, a bright orange-colored reaction mixture increasingly turned in dark brown and nearly clear solution (approximately $5 \mathrm{~min}$ ). The reaction mixture was stirred for additional $18 \mathrm{~h}$ at ambient temperature, resulting in turbidity of the solution, which can be attributed to micrometer-scale aggregates of the reverse micelles. As the reaction mixture was diluted with dry toluene, the turbidity of the solution decreased, resulting in a significant increase of the transmittance. To investigate whether the amphiphilic units could self-assemble reverse micelles 2 , we examined photophysical properties of the sample using absorption and fluorescence emission spectroscopies. The absorption and fluorescence measurements of the reverse micelles were conducted in sufficiently low concentrations $(c \leq 10 \mu \mathrm{M})$ where the turbidity of the solution completely disappeared. Under these conditions, the self-assembled aggregates were mostly dissociated into minimum-sized particles, exhibiting intrinsic spectroscopic properties of the chromophores involved in the reverse micelles. Compared with the spectral behaviors of $\mathbf{1}$, the absorption and fluorescence spectra of clear solutions showed broad, unstructured, and redshifted bands at most concentrations (Fig. 1A and 1B). It should be noted that the fluorescence emission spectra of the solutions $\left(\lambda_{\text {ex }} 378 \mathrm{~nm}\right)$ exhibited weak and broad emission of excimer-like interacting perylene chromophores at $545 \mathrm{~nm}$ along with disappearance of the monomeric emission of perylene units, implying the formation of chromophore aggregates. Indeed, this emission feature proved to be significantly different from those of mono-protonated and di-protonated species of $\mathbf{1}$ in ethanol, which were prepared by the reactions of 1 with 0.5 and 2.0 equiv of sulfuric acid, respectively. For comparison, fluorescence measurements have been performed on the ethanol solutions of these two species at two different concentrations ( $c 10.0$ and $0.1 \mu \mathrm{M}$ ), which are indicated in Fig. 3. Obviously, all these measurements revealed sharp monomeric perylene emissions with maxima at $c a .460 \mathrm{~nm}$, indicating that a set of the protonated systems have an essentially mono-disperse structures under these solvent conditions. From the above considerations, we rationalized that the formation of the reverse micelles through the self-assembly of the di-protonated triads took place in the toluene medium, where the fluorescence quenching of both the excited anthracene and the perylene groups should occur either by 
the intramolecular energy transfer or by collisional dissipation. In this regard, existence of the intramolecular energy transfer from the anthracene groups to the perylene core could be confirmed by the observation of excitation spectrum of 2 at $\lambda_{\text {em }}$ of the core at $500 \mathrm{~nm}$, which exhibited three distinct maxima attributed to the anthracene groups (Fig. 4). The fluorescence studies with modestly diluted solutions did not reveal significant changes in the spectral shape and intensity, but it appeared that highly diluted solutions displayed uniform spectral shapes of the monomeric perylene species with vibrational fine structures, similar to that of 1 (Fig. 5). These observations support the formation of reverse micelles where the fluorescent chromophores were either in close contact or interacting in the ground state at concentrations above a threshold level. It should also be mentioned that the chromophoric units of the clusters were chemically stable under the above reaction conditions. In fact, base treatment of $\mathbf{2}$ led to reproduction of $\mathbf{1}$, providing clear evidence that the self-assembly initiated with sulfuric acid resulted in the formation of chromophore aggregates.

\author{
$<$ Insert Fig. 3 here $>$ \\ <Insert Fig. 4 here $>$ \\ $<$ Insert Fig. 5 here $>$
}

To determine a value of critical micelle concentration $(\mathrm{cmc})$ of $\mathbf{2}$, we investigated titrations using various concentrations of the amphiphiles from 0.5 to $70 \mu \mathrm{M}$. At highly dilute concentrations of 2 below the cmc, where the protonated triad molecules gathering in the reverse micellar forms should become dissociated, the fluorescence spectra of the samples were identical to that of the monomeric perylene emission (Fig. 5), whose intensity should increase linearly with the solute concentrations. On the other hand, the formation of the reverse micelles leads to introduction of the radiationless deactivation channels due to the chromophore clustering, resulting in nonlinear dependency of the fluorescence intensities on the solute concentrations. For this reason, the titration experiments were performed by monitoring the fluorescence emission of the perylene chromophore at $470 \mathrm{~nm}$ with 
excitation of the anthracene group at $378 \mathrm{~nm}$. In the present case, the cmc can be defined phenomenologically from changes in the fluorescence output, whose intensity should increase or decrease linearly in a concentration range lower than the cmc due to the lack of concentration quenching. As illustrated in Fig. 6, the titration plots of fluorescence intensities showed nonlinear relationship in the concentration range greater than $3 \mu \mathrm{M}$, reaching a plateau above $40 \mu \mathrm{M}$. From a given inflection point in the fluorescence emission trajectory, we estimated the cmc value as $3 \mu \mathrm{M}$.

\author{
$<$ Insert Fig. 6 here $>$ \\ <Insert Fig. 7 here $>$ \\ <Insert Fig. 8 here $>$
}

In light of the above spectroscopic observations, it is important to have insights into morphology of the self-assembled structure. Thus, we turned to atomic force microscope (AFM) investigation employing airdried samples cast on the freshly cleaved highly oriented pyrolytic graphite (HOPG) substrates due to experimental limitations encountered with the use of solution samples. As seen in Fig. 7, AFM image of 1 in dry toluene $(c 0.1 \mathrm{mM})$ showed large leaf-shaped objects that was attributed to microcrystalline aggregates (Fig. 7A), while that of the highly diluted solution $(c 5.0 \mu \mathrm{M})$ exhibited small ill-defined objects, judging from their height profile, with an average height less than $2 \mathrm{~nm}$ (Fig. 7B). On the other hand, the AFM analysis of 2 showed a number of small and medium-sized spherical objects in addition to structurally ill-defined or amorphous objects which differ significantly from those of 1 (Fig. 7C). In fact, we reproducibly obtained small-sized spherical objects when the solutions at different concentrations in toluene were cast on the HOPG substrates. To investigate the spectroscopic property of the drop-cast sample, we carried out fluorescence measurement on a thin film of $\mathbf{2}$ cast on a glass plate. In Fig. 8, the fluorescence spectrum for the drop-cast film showed a broad unstructured band with maximum around $540 \mathrm{~nm}$, indicating its similarity to that of 2 dispersed in the toluene medium. The reproducible AFM results and the observed fluorescence property suggest that the small-sized 
peaks can be attributed to the individual reverse micelles and thus the medium-sized peaks should correspond to their assemblies. A cross-sectional view of the AFM image (Fig. 7D) indicated that small spherical objects appeared to have an average height about $4 \mathrm{~nm}$. From the height analyses for 100 spherical peaks, we found that nearly $90 \%$ of the peaks gave the height less than $10 \mathrm{~nm}$. These results suggest the amphiphiles diffusing in the isotropic toluene medium should self-assemble into the stable globular structures with impressively narrow diameter distributions centered around the nanoscopic dimension. For additional aggregate size determination, dynamic light scattering (DLS) measurements have been performed on the reverse micelles. However, attempts to record particle size distributions failed due to experimental limitations of the setup.

\author{
$<$ Insert Fig. 9 here $>$ \\ $<$ Insert Fig. 10 here $>$ \\ $<$ Insert Fig. 11 here $>$
}

At this point, it must be noted that the amount of water added to the reaction mixture would be important in determining aggregate sizes and stabilities in the course of reverse micelle formations. To observe the effects of water contents in the self-assembly processes, we investigated the spectroscopic and microscopic behavior of a series of the reverse micelles at the $W_{0}$ values of 30,50,100, and 200. In comparison, absorption and fluorescence spectra of these four types of reversed micelles showed spectral shapes almost indistinguishable from those of the reverse micelles at $W_{0}=10$ (Fig. 9), while the cmc titration studies with all these samples $\left(W_{0}=30,50,100\right.$ and 200) gave reproducible profiles with the approximately constant cmc values (Fig. 10). Additionally, AFM analyses of the reverse micelles at $W_{0}=30$ and 50 confirmed that the volume increments of water did not result in continuous growth of the globular structures, giving average peak heights less than $10 \mathrm{~nm}$ (Fig. 11). The results from these experiments strongly suggest that the reverse micelles should have a uniform aggregate size 
independent of the water/surfactant ratio, revealing a unique relation between specific geometrical configuration of the amphiphilic molecules and intrinsic size of the reverse micelles.

\section{Conclusion}

We demonstrate that the anthracene-perylene triads self-assemble into the nanostructured reverse micelles upon protonation of the tertiary amines in the toluene medium. It has been shown that this triad system makes it possible to achieve efficient energy transfer from the peripheral anthracene antennae to the perylene core, rendering the reverse micelles potent light-harvesting complexes. As far as we are aware, our model studied here represents the first example of light-harvesting reverse micelles composed of a spherical array of antenna pigments. Research on application and further development of the reverse micelle systems is currently in progress.

\section{Experimental}

\subsection{General}

All solvents and reagents were of reagent grade quality from Wako Pure Chemicals and Tokyo Chemical Industry (TCI) used without further purification. The ${ }^{1} \mathrm{H}$ and ${ }^{13} \mathrm{C}$ nuclear magnetic resonance (NMR) spectra operating at the frequencies of 300 and $75 \mathrm{MHz}$, respectively, were recorded on a JEOL JNM-AL300 spectrometer in chloroform- $d\left(\mathrm{CDCl}_{3}\right)$. Chemical shifts are reported in parts per million (ppm) relative to TMS and the solvent used as internal standards, and the coupling constants are reported in hertz $(\mathrm{Hz})$. Fourier transform infrared (FTIR) spectra were recorded on JASCO FT/IR-410 and Shimadzu FTIR-8200A spectrometers. UV-vis and fluorescence (excitation) spectra were recorded on a JASCO V-530 spectrophotometer and a JASCO FP-6200 spectrofluorometer, respectively. Melting points were measured with a Yanaco MP-S3 melting point apparatus. Laser desorption ionization time of flight (LDI-TOF) mass spectra were recorded on an Applied Biosystems Voyager-DE PRO mass spectrometer. High resolution mass spectrometry (HRMS) was performed on a JEOL JMS-T100CS. 
Elemental analyses were performed by Thermo Flash EA 1112 and JSL Model JM 10 instruments. The atomic force microscope (AFM) analyses were performed on a Veeco NanoScope IIIa microscope.

\subsection{Preparation and characterization of new compounds}

\subsubsection{1,8-Bis(2-ethylhexyl)anthracene (3)}

This compound was prepared according to already published reaction protocol. ${ }^{13,14}$ To a solution containing 1,3-bis(diphenylphosphino)propane]nickel(II) dichloride ([Ni(dppp) $)_{2} \mathrm{Cl}_{2}, 45 \mathrm{mg}, 0.083$ mmol) and 2-ethylhexylmagnesium bromide, which was prepared from 2-ethylhexyl bromide (7.1 mL, $41.1 \mathrm{mmol})$ and magnesium $(1.00 \mathrm{~g}, 41.1 \mathrm{mmol})$, in ether $(20 \mathrm{~mL})$ was added 1,8-dichloroanthracene $(1.00 \mathrm{~g}, 4.05 \mathrm{mmol})$ in small portions under gentle reflux. After the reaction mixture was refluxed for an additional 6 hours, it was cooled to $0{ }^{\circ} \mathrm{C}$, quenched with water $(10 \mathrm{~mL})$ and $5 \% \mathrm{HCl}_{\mathrm{aq}}(20 \mathrm{~mL})$ The resulting mixture was extracted with hexane $(20 \mathrm{~mL} \times 2)$, washed with water $(20 \mathrm{~mL} \times 2), \mathrm{NaHCO}_{3 \mathrm{aq}}$ $(20 \mathrm{~mL} \times 2)$ and brine $(20 \mathrm{~mL})$, dried over $\mathrm{Na}_{2} \mathrm{SO}_{4}$ and concentrated in vacuo. Purification of the residue by flush column chromatography on silica gel (eluent: hexane) gave 1,8-bis(2ethylhexyl)anthracene (1.43 g, 88\%) as a pale yellow oil: IR (NaCl) $3048 \mathrm{~cm}^{-1}(\mathrm{C}-\mathrm{H}), 2959 \mathrm{~cm}^{-1}(\mathrm{C}-\mathrm{H})$, $2928 \mathrm{~cm}^{-1}(\mathrm{C}-\mathrm{H}), 2858 \mathrm{~cm}^{-1}(\mathrm{C}-\mathrm{H}) ;{ }^{1} \mathrm{H}$ NMR $\left(\mathrm{CDCl}_{3}\right) \delta 0.8-1.0(\mathrm{~m}, 12 \mathrm{H}, \mathrm{Me}), 1.2-1.5\left(\mathrm{~m}, 16 \mathrm{H}, \mathrm{CH}_{2}\right)$, 1.9-2.0 (m, 2H, CH), $3.11\left(\mathrm{~d}, J=7.3 \mathrm{~Hz}, 4 \mathrm{H}, \mathrm{CH}_{2}\right), 7.24(\mathrm{~d}, J=6.5 \mathrm{~Hz}, 2 \mathrm{H}, \mathrm{Ar} H), 7.34(\mathrm{dd}, J=6.5$ and $8.4 \mathrm{~Hz}, 2 \mathrm{H}, \operatorname{Ar} H), 7.82(\mathrm{~d}, J=8.4 \mathrm{~Hz}, 2 \mathrm{H}, \operatorname{Ar} H), 8.38(\mathrm{~s}, 1 \mathrm{H}, \operatorname{Ar} H), 8.80(\mathrm{~s}, 1 \mathrm{H}, \operatorname{Ar} H)$; ${ }^{13} \mathrm{C} \mathrm{NMR}$ $\left(\mathrm{CDCl}_{3}\right) \delta 10.6\left(\mathrm{CH}_{3}\right), 14.0\left(\mathrm{CH}_{3}\right), 23.1\left(\mathrm{CH}_{2}\right), 25.7\left(\mathrm{CH}_{2}\right), 25.8\left(\mathrm{CH}_{2}\right), 28.7\left(\mathrm{CH}_{2}\right), 32.7\left(\mathrm{CH}_{2}\right), 32.8$ $\left(\mathrm{CH}_{2}\right), 38.3\left(\mathrm{CH}_{2}\right), 39.8(\mathrm{CH}), 119.4(\mathrm{CH}), 124.9(\mathrm{CH}), 126.2(\mathrm{CH}), 126.6(\mathrm{CH}), 127.7(\mathrm{CH}), 130.7(C)$, 132.0 (C), 138.1 (C). Anal Calcd for $\mathrm{C}_{30} \mathrm{H}_{42}$ : C, 89.49; H, 10.51. Found: C, 89.20; H, 10.72.

\subsubsection{4,5-Bis(2-ethylhexyl)-9-anthracenecarbaldehyde (4)}

This compound was prepared according to already published reaction protocol. ${ }^{15}$ To a solution containing 1,8-bis(2-ethylhexyl)anthracene (1.20 g, $2.98 \mathrm{mmol})$ and dichloromethyl methyl ether (1.6 $\mathrm{mL}, 18.1 \mathrm{mmol})$ in dichloromethane $(20 \mathrm{~mL})$ was added a solution of titanium tetrachloride $(1.3 \mathrm{~mL}$, 
$9.39 \mathrm{mmol})$ in dichloromethane $(5 \mathrm{~mL})$ dropwise at $0{ }^{\circ} \mathrm{C}$. After the reaction mixture was stirred for an additional 4 hours at ambient temperature, it was cooled to $0{ }^{\circ} \mathrm{C}$, quenched with water $(20 \mathrm{~mL})$ and $\mathrm{NaHCO}_{3 \mathrm{aq}}(40 \mathrm{~mL})$. The resulting mixture was extracted with dichloromethane $(40 \mathrm{~mL} \times 2)$, washed with water $(20 \mathrm{~mL} \times 2), \mathrm{NaHCO}_{3 \mathrm{aq}}(20 \mathrm{~mL} \times 2)$ and brine $(20 \mathrm{~mL})$, dried over $\mathrm{Na}_{2} \mathrm{SO}_{4}$ and concentrated in vacuo. Purification of the residue by flush column chromatography on silica gel (eluent: hexane/chloroform $=50 / 50)$ gave 4,5-bis(2-ethylhexyl)-9-anthracenecarbaldehyde $(1.14 \mathrm{~g}, 89 \%)$ as a dark brown oil: IR (NaCl) $2958 \mathrm{~cm}^{-1}(\mathrm{C}-\mathrm{H}), 2927 \mathrm{~cm}^{-1}(\mathrm{C}-\mathrm{H}), 2858 \mathrm{~cm}^{-1}(\mathrm{C}-\mathrm{H}), 1670 \mathrm{~cm}^{-1}(\mathrm{C}=\mathrm{O})$; MS (LDI) $m / z 430\left(\mathrm{M}^{+}\right) ;{ }^{1} \mathrm{H}$ NMR $\left(\mathrm{CDCl}_{3}\right) \delta$ 0.8-1.0 (m, 12H, Me), 1.2-1.5 (m, 16H, $\left.\mathrm{CH}_{2}\right), 1.9-2.0(\mathrm{~m}, 2 \mathrm{H}$, $\mathrm{CH}), 3.16\left(\mathrm{~d}, J=7.4 \mathrm{~Hz}, 4 \mathrm{H}, \mathrm{CH}_{2}\right), 7.36(\mathrm{~d}, J=6.8 \mathrm{~Hz}, 2 \mathrm{H}, \mathrm{Ar} H), 7.58(\mathrm{dd}, J=6.8$ and $9.0 \mathrm{~Hz}, 2 \mathrm{H}$, $\operatorname{Ar} H), 8.77(\mathrm{~d}, J=9.0 \mathrm{~Hz}, 2 \mathrm{H}, \operatorname{Ar} H), 9.17(\mathrm{~s}, 1 \mathrm{H}, \mathrm{Ar} H), 11.51(\mathrm{~s}, 1 \mathrm{H}, \mathrm{CHO}) ;{ }^{13} \mathrm{C} \mathrm{NMR}\left(\mathrm{CDCl}_{3}\right) \delta 10.5$ $\left(\mathrm{CH}_{3}\right), 14.0\left(\mathrm{CH}_{3}\right), 23.0\left(\mathrm{CH}_{2}\right), 25.6\left(\mathrm{CH}_{2}\right), 25.7\left(\mathrm{CH}_{2}\right), 28.6\left(\mathrm{CH}_{2}\right), 32.5\left(\mathrm{CH}_{2}\right), 32.6\left(\mathrm{CH}_{2}\right), 38.4\left(\mathrm{CH}_{2}\right)$, $40.1(\mathrm{CH}), 121.7(\mathrm{CH}), 126.6(\mathrm{CH}), 127.2(\mathrm{CH}), 128.4(\mathrm{CH}), 129.8(C), 132.0(C), 139.0(C), 194.2$ $(C H)$. Anal Calcd for $\mathrm{C}_{31} \mathrm{H}_{42} \mathrm{O}: \mathrm{C}, 86.46 ; \mathrm{H}, 9.83$. Found: C, 86.21; H, 9.92.

\subsubsection{4,5-Bis(2-ethylhexyl)-9-(hydroxymethyl)anthracene (5)}

To a solution of 1,8-bis(2-ethylhexyl)-9-anthracenecarbaldehyde (1.13 g, $2.62 \mathrm{mmol})$ in ethanol (20 $\mathrm{mL})$ was added sodium borohydride $(0.2 \mathrm{~g}, 5.29 \mathrm{mmol})$ in small portions at $0{ }^{\circ} \mathrm{C}$. After the reaction mixture was stirred for an additional 18 hours at ambient temperature, it was quenched with water (20 $\mathrm{mL})$ and $5 \% \mathrm{HCl}_{\mathrm{aq}}(20 \mathrm{~mL})$. The resulting mixture was extracted with ethyl acetate $(40 \mathrm{~mL} \times 2)$, washed with water $(20 \mathrm{~mL}), \mathrm{NaHCO}_{3 \mathrm{aq}}(20 \mathrm{~mL} \times 2)$ and brine $(20 \mathrm{~mL})$, dried over $\mathrm{Na}_{2} \mathrm{SO}_{4}$ and concentrated in vacuo. Purification of the residue by flush column chromatography on silica gel (eluent: chloroform) gave 4,5-bis(2-ethylhexyl)-9-(hydroxymethyl)anthracene (0.99 g, 87\%) as a pale yellow oil: IR (NaCl) $3303 \mathrm{~cm}^{-1}(\mathrm{O}-\mathrm{H}), 2958 \mathrm{~cm}^{-1}$ (C-H), $2927 \mathrm{~cm}^{-1}$ (C-H), $2858 \mathrm{~cm}^{-1}$ (C-H); MS(LDI) $m / z 432$ $\left(\mathrm{M}^{+}\right) ;{ }^{1} \mathrm{H}$ NMR $\left(\mathrm{CDCl}_{3}\right) \delta$ 0.8-1.0 (m, 12H, Me), 1.2-1.5 (m, 16H, $\left.\mathrm{CH}_{2}\right), 1.85$ (brs, 1H, $\left.\mathrm{OH}\right), 1.9-2.0$ (m, 2H, CH), $3.13\left(\mathrm{~d}, J=7.3 \mathrm{~Hz}, 4 \mathrm{H}, \mathrm{CH}_{2}\right), 5.62\left(\mathrm{~s}, 2 \mathrm{H}, \mathrm{CH}_{2}\right), 7.29$ (d, $\left.J=6.7 \mathrm{~Hz}, 2 \mathrm{H}, \mathrm{ArH}\right), 7.45$ (dd, $J=6.7$ and $8.9 \mathrm{~Hz}, 2 \mathrm{H}, \operatorname{Ar} H), 8.26(\mathrm{~d}, J=8.9 \mathrm{~Hz}, 2 \mathrm{H}, \operatorname{Ar} H), 8.90(\mathrm{~s}, 1 \mathrm{H}, \operatorname{Ar} H) ;{ }^{13} \mathrm{C} \mathrm{NMR}\left(\mathrm{CDCl}_{3}\right) \delta$ 
$10.5\left(\mathrm{CH}_{3}\right), 14.0\left(\mathrm{CH}_{3}\right), 23.1\left(\mathrm{CH}_{2}\right), 25.6\left(\mathrm{CH}_{2}\right), 25.7\left(\mathrm{CH}_{2}\right), 28.6\left(\mathrm{CH}_{2}\right), 32.6\left(\mathrm{CH}_{2}\right), 38.4\left(\mathrm{CH}_{2}\right), 38.5$ $\left(\mathrm{CH}_{2}\right), 39.8(\mathrm{CH}), 57.8\left(\mathrm{CH}_{2}\right), 121.1(\mathrm{CH}), 122.2(\mathrm{CH}), 125.9(\mathrm{CH}), 126.1(\mathrm{CH}), 130.3(\mathrm{C}), 130.4(\mathrm{C})$, 132.0 (C), 138.7 (C). Anal Calcd for $\mathrm{C}_{31} \mathrm{H}_{44} \mathrm{O}: \mathrm{C}, 86.05 ; \mathrm{H}, 10.25$. Found: $\mathrm{C}, 86.02 ; \mathrm{H}, 10.39$.

\subsubsection{9-(Chloromethyl)-4,5-bis(2-ethylhexyl)anthracene (6)}

To a solution of 4,5-bis(2-ethylhexyl)-9-(hydroxymethyl)anthracene $(1.80 \mathrm{~g}, 4.18 \mathrm{mmol})$ in dichloromethane $(20 \mathrm{~mL})$ was added a solution of thionyl chloride $(3.0 \mathrm{~mL}, 41.4 \mathrm{mmol})$ in dichloromethane $(10 \mathrm{~mL})$ dropwise at $0{ }^{\circ} \mathrm{C}$. After the reaction mixture was stirred for an additional 2 hours at $0{ }^{\circ} \mathrm{C}$, it was concentrated in vacuo to gave 9-(chloromethyl)-4,5-bis(2-ethylhexyl)anthracene (1.86 g, 99\%) as a yellow-green oil: IR (KBr) $2958 \mathrm{~cm}^{-1}(\mathrm{C}-\mathrm{H}), 2927 \mathrm{~cm}^{-1}(\mathrm{C}-\mathrm{H}), 2871 \mathrm{~cm}^{-1}(\mathrm{C}-\mathrm{H})$; MS (LDI) $m / z 450\left(\mathrm{M}^{+}\right) ;{ }^{1} \mathrm{H}$ NMR $\left(\mathrm{CDCl}_{3}\right) \delta 0.8-1.0(\mathrm{~m}, 12 \mathrm{H}, \mathrm{Me}), 1.2-1.5\left(\mathrm{~m}, 16 \mathrm{H}, \mathrm{CH}_{2}\right), 1.8-2.0(\mathrm{~m}, 2 \mathrm{H}$, $\mathrm{CH}), 3.13\left(\mathrm{~d}, J=7.2 \mathrm{~Hz}, 4 \mathrm{H}, \mathrm{CH}_{2}\right), 5.60\left(\mathrm{~s}, 2 \mathrm{H}, \mathrm{CH}_{2}\right), 7.30(\mathrm{~d}, J=6.8 \mathrm{~Hz}, 2 \mathrm{H}, \mathrm{ArH}), 7.51(\mathrm{dd}, J=6.8$ and $8.8 \mathrm{~Hz}, 2 \mathrm{H}, \operatorname{Ar} H), 8.18(\mathrm{~d}, J=8.8 \mathrm{~Hz}, 2 \mathrm{H}, \operatorname{Ar} H), 8.93(\mathrm{~s}, 1 \mathrm{H}, \operatorname{Ar} H) ;{ }^{13} \mathrm{C} \mathrm{NMR}\left(\mathrm{CDCl}_{3}\right) \delta 10.5$ $\left(\mathrm{CH}_{3}\right), 14.0\left(\mathrm{CH}_{3}\right), 23.1\left(\mathrm{CH}_{2}\right), 25.6\left(\mathrm{CH}_{2}\right), 28.6\left(\mathrm{CH}_{2}\right), 32.6\left(\mathrm{CH}_{2}\right), 38.4\left(\mathrm{CH}_{2}\right), 39.8\left(\mathrm{CH}_{2}\right), 39.9(\mathrm{CH})$, $121.7(\mathrm{CH}), 122.0(\mathrm{CH}), 126.3(\mathrm{CH}), 126.5(\mathrm{CH}), 128.5(C), 130.3(C), 138.9(C)$. Anal Calcd for $\mathrm{C}_{31} \mathrm{H}_{43} \mathrm{Cl}$ : C, 82.53; H, 9.61. Found: C, 82.79; H, 9.61.

\subsubsection{4,5-Bis(2-ethylhexyl)-9-(phthalimidomethyl)anthracene (7)}

To a suspension containing phthalimide $(0.41 \mathrm{~g}, 2.79 \mathrm{mmol})$ and potassium carbonate $(2.6 \mathrm{~g}, 18.8$ mmol) in $\quad N, N$-dimethylformamide $(20 \quad \mathrm{~mL}) \quad$ was added 9-(chloromethyl)-4,5-bis(2ethylhexyl)anthracene $(1.06 \mathrm{~g}, 2.35 \mathrm{mmol})$ at ambient temperature. After the reaction mixture was stirred for an additional 18 hours at ambient temperature, it was filtered through Celite and washed with ethyl acetate $(80 \mathrm{~mL})$. The filtrate was washed with water $(20 \mathrm{~mL})$ and brine $(20 \mathrm{~mL})$, dried over $\mathrm{Na}_{2} \mathrm{SO}_{4}$ and concentrated in vacuo. Purification of the residue by flush column chromatography on silica gel (eluent: hexane/chloroform $=50 / 50$ ) gave 4,5-bis(2-ethylhexyl)-9(phthalimidomethyl)anthracene $\left(0.99 \mathrm{~g}, 75 \%\right.$ ) as a pale yellow solid: $\mathrm{mp} 90-91{ }^{\circ} \mathrm{C}$; IR (KBr) $2958 \mathrm{~cm}^{-1}$ 
(C-H), $2925 \mathrm{~cm}^{-1}(\mathrm{C}-\mathrm{H}), 2858 \mathrm{~cm}^{-1}(\mathrm{C}-\mathrm{H}), 1772 \mathrm{~cm}^{-1}(\mathrm{C}=\mathrm{O}), 1716 \mathrm{~cm}^{-1}(\mathrm{C}=\mathrm{O})$; MS (LDI) $\mathrm{m} / z$ 561(M ${ }^{+}$); ${ }^{1} \mathrm{H}$ NMR $\left(\mathrm{CDCl}_{3}\right) \delta$ 0.8-1.0 (m, 12H, Me), 1.2-1.5 (m, 16H, $\left.\mathrm{CH}_{2}\right), 1.8-2.0(\mathrm{~m}, 2 \mathrm{H}, \mathrm{CH}), 3.12(\mathrm{~d}, J=7.2$ $\left.\mathrm{Hz}, 4 \mathrm{H}, \mathrm{CH}_{2}\right), 5.82\left(\mathrm{~s}, 2 \mathrm{H}, \mathrm{CH}_{2}\right), 7.22(\mathrm{~d}, J=6.7 \mathrm{~Hz}, 2 \mathrm{H}, \mathrm{Ar} H), 7.48(\mathrm{dd}, J=6.7$ and $8.9 \mathrm{~Hz}, 2 \mathrm{H}, \mathrm{Ar} H)$, $7.57(\mathrm{dd}, J=3.0$ and $5.5 \mathrm{~Hz}, 2 \mathrm{H}, \mathrm{ArH}), 7.71(\mathrm{dd}, J=3.0$ and $5.5 \mathrm{~Hz}, 2 \mathrm{H}, \operatorname{Ar} H), 8.49(\mathrm{~d}, J=8.9 \mathrm{~Hz}, 2 \mathrm{H}$, $\mathrm{Ar} H), 8.93(\mathrm{~s}, 1 \mathrm{H}, \mathrm{Ar} H) ;{ }^{13} \mathrm{C} \mathrm{NMR}\left(\mathrm{CDCl}_{3}\right) \delta 10.5\left(\mathrm{CH}_{3}\right), 14.0\left(\mathrm{CH}_{3}\right), 23.1\left(\mathrm{CH}_{2}\right), 25.5\left(\mathrm{CH}_{2}\right), 25.6$ $\left(\mathrm{CH}_{2}\right), 28.6\left(\mathrm{CH}_{2}\right), 32.6\left(\mathrm{CH}_{2}\right), 36.0\left(\mathrm{CH}_{2}\right), 38.4\left(\mathrm{CH}_{2}\right), 38.5\left(\mathrm{CH}_{2}\right), 40.0(\mathrm{CH}), 121.5(\mathrm{CH}), 123.0(\mathrm{CH})$, 123.2 (CH), $125.7(\mathrm{CH}), 125.9(\mathrm{CH}), 127.2(C), 130.1(C), 131.2(C), 132.0(C), 133.9(\mathrm{CH}), 138.6(C)$, 168.5 (C). Anal Calcd for $\mathrm{C}_{39} \mathrm{H}_{47} \mathrm{NO}_{2}:$ C, 83.38; H, 8.43; N, 2.49. Found: C, 83.18; H, 8.51; N, 2.46 .

\subsubsection{9-(Aminomethyl)-4,5-bis(2-ethylhexyl)anthracene (8)}

To a solution of 4,5-bis(2-ethylhexyl)-9-(phthalimidomethyl)anthracene (0.58 g, $1.03 \mathrm{mmol})$ in THF $(20 \mathrm{~mL})$ was slowly added hydrazine monohydrate $(1.0 \mathrm{~mL}, 20.6 \mathrm{mmol})$ at ambient temperature and heated at reflux. After the reaction mixture was refluxed for an additional 2 hours, it was filtered through Celite and washed with ethyl acetate $(80 \mathrm{~mL})$. The filtrate was washed with water $(20 \mathrm{~mL})$ and brine $(20 \mathrm{~mL})$, dried over $\mathrm{Na}_{2} \mathrm{SO}_{4}$ and concentrated in vacuo. Purification of the residue by flush column chromatography on silica gel (eluent: methanol/chloroform =1/20) gave 9-(aminomethyl)-4,5bis(2-ethylhexyl)anthracene $(0.41 \mathrm{~g}, 92 \%)$ as a pale yellow oil; IR ( $\mathrm{NaCl}) 3369$ and $3288(\mathrm{NH}), 3007$, 2959, 2928, 2872 and $2858(\mathrm{CH})$; HRMS (ESI) $\mathrm{m} / z$ calcd for $\mathrm{C}_{31} \mathrm{H}_{45} \mathrm{NNa}$ : 454.3450, found 454.3425; ${ }^{1} \mathrm{H}$ NMR $\left(\mathrm{CDCl}_{3}\right) \delta$ 0.8-1.0 (m, 12H, Me), 1.2-1.5 (m, 16H, $\left.\mathrm{CH}_{2}\right), 1.6-1.7$ (brs, 2H, $\left.\mathrm{NH}_{2}\right), 1.9-2.0(\mathrm{~m}$, 2H, CH), $3.13\left(\mathrm{~d}, J=7.4 \mathrm{~Hz}, 4 \mathrm{H}, \mathrm{CH}_{2}\right), 4.78\left(\mathrm{~s}, 2 \mathrm{H}, \mathrm{CH}_{2}\right), 7.27(\mathrm{~d}, J=6.7 \mathrm{~Hz}, 2 \mathrm{H}, \mathrm{ArH}), 7.43$ (dd, $J=$ 6.7 and $8.9 \mathrm{~Hz}, 2 \mathrm{H}, \operatorname{Ar} H), 8.19(\mathrm{~d}, J=8.9 \mathrm{~Hz}, 2 \mathrm{H}, \mathrm{Ar} H), 8.83(\mathrm{~s}, 1 \mathrm{H}, \operatorname{Ar} H) ;{ }^{13} \mathrm{C} \mathrm{NMR}\left(\mathrm{CDCl}_{3}\right) \delta 10.5$ $\left(\mathrm{CH}_{3}\right), 14.0\left(\mathrm{CH}_{3}\right), 23.1\left(\mathrm{CH}_{2}\right), 25.5\left(\mathrm{CH}_{2}\right), 25.6\left(\mathrm{CH}_{2}\right), 28.6\left(\mathrm{CH}_{2}\right), 32.6\left(\mathrm{CH}_{2}\right), 38.4\left(\mathrm{CH}_{2}\right), 38.5\left(\mathrm{CH}_{2}\right)$, $38.7\left(\mathrm{CH}_{2}\right), 40.0(\mathrm{CH}), 119.6(\mathrm{CH}), 122.0(\mathrm{CH}), 125.6(\mathrm{CH}), 126.0(\mathrm{CH}), 129.4(C), 130.4(C), 135.6$ (C), $138.9(C)$. 
4.2.7. N,N'-Bis(anthracenemethyl)-substituted 1,3,8,10-tetrahydro-2,9-diazadibenzo[cd,lm]perylene (1)

To an argon-purged suspension of 9-(aminomethyl)-4,5-bis(2-ethylhexyl)anthracene (0.39 g, 0.90 mmol) and potassium carbonate $(0.1 \mathrm{~g}, 0.72 \mathrm{mmol})$ in anhydrous THF $(2.5 \mathrm{~mL})$, was added 3,4,9,10tetra(chloromethyl)perylene $(0.020 \mathrm{~g}, 0.045 \mathrm{mmol})$ at ambient temperature. After the reaction mixture was stirred for an additional 18 hours at ambient temperature, it was diluted with anhydrous THF (40 $\mathrm{mL})$, filtered through Celite and washed with additional THF $(20 \mathrm{~mL})$. The filtrate was concentrated in vacuo, and the residue was chromatographed using silica gel (eluent: chloroform), giving 1 (0.038 g, $72 \%)$ as yellow powders; UV (toluene) $360 \mathrm{~nm}(\varepsilon 13,200), 378(\varepsilon 20,900), 401(\varepsilon 24,800), 432(\varepsilon$ 35,100) and $461(\varepsilon 44,000)$; IR $(\mathrm{NaCl}) 2956 \mathrm{~cm}^{-1}(\mathrm{C}-\mathrm{H}), 2924 \mathrm{~cm}^{-1}(\mathrm{C}-\mathrm{H}), 2856 \mathrm{~cm}^{-1}(\mathrm{C}-\mathrm{H})$; HRMS (ESI) $m / z$ calcd for $\mathrm{C}_{86} \mathrm{H}_{102} \mathrm{~N}_{2} \mathrm{Na}$ : 1163.8043, found $1163.8053 ;{ }^{1} \mathrm{H}$ NMR $\left(\mathrm{CDCl}_{3}\right) \delta 0.8-1.0(\mathrm{~m}, 24 \mathrm{H}$, $M e), 1.2-1.5\left(\mathrm{~m}, 32 \mathrm{H}, \mathrm{CH}_{2}\right), 1.9-2.0(\mathrm{~m}, 4 \mathrm{H}, \mathrm{CH}), 3.15\left(\mathrm{~d}, J=7.3 \mathrm{~Hz}, 8 \mathrm{H}, \mathrm{CH}_{2}\right), 4.12\left(\mathrm{~s}, 8 \mathrm{H}, \mathrm{C} H_{2}\right), 4.71$ (s, 4H, $\left.\mathrm{CH}_{2}\right), 7.11(\mathrm{~d}, J=7.8 \mathrm{~Hz}, 4 \mathrm{H}, \operatorname{Ar} H), 7.27(\mathrm{~d}, J=6.7 \mathrm{~Hz}, 4 \mathrm{H}, \operatorname{Ar} H), 7.38(\mathrm{dd}, J=6.7 \mathrm{and} 8.9 \mathrm{~Hz}$, 4H, ArH), $8.04(\mathrm{~d}, J=7.8 \mathrm{~Hz}, 4 \mathrm{H}, \operatorname{Ar} H), 8.31(\mathrm{~d}, J=8.9 \mathrm{~Hz}, 4 \mathrm{H}, \operatorname{Ar} H), 8.91(\mathrm{~s}, 2 \mathrm{H}, \operatorname{Ar} H) ;{ }^{13} \mathrm{C} \mathrm{NMR}$ $\left(\mathrm{CDCl}_{3}\right) \delta 10.6\left(\mathrm{CH}_{3}\right), 14.0\left(\mathrm{CH}_{3}\right), 23.1\left(\mathrm{CH}_{2}\right), 25.7\left(\mathrm{CH}_{2}\right), 25.8\left(\mathrm{CH}_{2}\right), 28.7\left(\mathrm{CH}_{2}\right), 32.7\left(\mathrm{CH}_{2}\right), 38.5$ $\left(\mathrm{CH}_{2}\right), 38.6\left(\mathrm{CH}_{2}\right), 39.7(\mathrm{CH}), 53.0\left(\mathrm{CH}_{2}\right), 56.4\left(\mathrm{CH}_{2}\right), 119.3(\mathrm{CH}), 120.4(\mathrm{CH}), 123.4(\mathrm{CH}), 123.5(\mathrm{CH})$, $125.4(C \mathrm{H}), 125.9(\mathrm{CH}), 128.2(C), 129.5(C), 130.1(\mathrm{CH}), 130.2(C \mathrm{H}), 130.4(C \mathrm{H}), 131.7(C), 132.8$ (C), $138.5(C)$.

\subsection{Typical experimental procedure for AFM analyses}

The reaction mixture diluted with dry toluene $(c 0.1 \mathrm{mM})$ was drop-cast on to the HOPG. Airdried sample of the reaction mixture was examined by carrying out measurements in tapping mode.

\section{Acknowledgements}


This research was supported by Iketani Foundation, a Grant-in-Aid for Scientific Research and Nanotechnology Network Project (Kyushu-area Nanotechnology Network) from the Ministry of Education, Culture, Sports, Science and Technology (MEXT), Japan.

\section{Appendix A. Supplementary data}

${ }^{1} \mathrm{H}$ and ${ }^{13} \mathrm{C}$ NMR spectra for all new compounds. Supplementary data associated with this article can be found, in the online version.

\section{References}

1. (a) K. E. Sapsford, L. Berti, I. L. Medintz, Angew. Chem., Int. Ed. 45 (2006) 4562; (b) T. S. Balaban, Acc. Chem. Res. 38 (2005) 612.

2. (a) C. Devadoss, P. Bharathi, J. S. Moore, J. Am. Chem. Soc. 118 (1996) 9635; (b) A. Adronov, J. M. J. Fréchet, Chem. Commun. (2000) 1701; (c) U. Hahn, M. Gorka, F. Vögtle, V. Vicinelli, P. Ceroni, M. Maestri, V. Balzani, Angew. Chem., Int. Ed. 41 (2002) 3595; (d) M. -S. Choi, T. Yamazaki, I. Yamazaki, T. Aida, Angew. Chem., Int. Ed. 43 (2004) 150.

3. (a) M. Takahashi, T. Odagi, H. Tomita, T. Oshikawa, M. Yamashita, Tetrahedron Lett. 44 (2003) 2455; (b) M. Takahashi, H. Morimoto, Y. Suzuki, T. Odagi, M. Yamashita, H. Kawai, Tetrahedron 60 (2004) 11771; (c) M. Takahashi, H. Morimoto, Y. Suzuki, M. Yamashita, H. Kawai, Y. Sei, K. Yamaguchi, Tetrahedron 62 (2006) 3065; (d) M. Takahashi, H. Morimoto, Y. Suzuki, M. Yamashita, H. Kawai, Polymer Prepr. 45 (2004) 959.

4. (a) M. Takahashi, H. Morimoto, K. Miyake, M. Yamashita, H. Kawai, Y. Sei, K. Yamaguchi, Chem. Commun. (2006) 3084; (b) M. Takahashi, H. Morimoto, K. Miyake, H. Kawai, Y. Sei, K. Yamaguchi, M. Yamashita, T. Sengoku, H. Yoda, New J. Chem. 32 (2008) 547. 
5. (a) K. T. Nielsen, H. Spanggaard, F. C. Krebs, Macromolecules 38 (2005) 1180; (b) M. Chen, K. P. Ghiggino, A. W. H. Mau, W. H. F. Sasse, S. H. Thang, G. J. Wilson, Macromolecules 38 (2005) 3475; (c) A. Tsuda, A. Osuka, Science 293 (2001) 79.

6. (a) A. Del Guerzo, A. G. L. Olive, J. Reichwagen, H. Hopf, J. -P. Desvergne, J. Am. Chem. Soc. 127 (2005) 17984; (b) C. Röger, M. G. Müller, M. Lysetska, Y. Miloslavina, A. R. Holzwarth, F. Würthner, J. Am. Chem. Soc. 128 (2006) 6542.

7. (a) F. J. M. Hoeben, I. O. Shklyarevskiy, M. J. Pouderoijen, H. Engelkamp, A. P. H. J. Schenning, P. C. M. Christianen, J. C. Maan, E. W. Meijer, Angew. Chem., Int. Ed. 45 (2006) 1232; (b) K. L. Metera, H. Sleiman, Macromolecules 40 (2007) 3733.

8. (a) K. Sugiyasu, N. Fujita, S. Shinkai, Angew. Chem., Int. Ed. 43 (2004) 1229; (b) A. Ajayaghosh, V. K. Praveen, C. Vijayakumar, S. J. George, Angew. Chem., Int. Ed. 46 (2007) 6260.

9. (a) R. F. Kelly, R. H. Goldsmith, M. R. Wasielewski, J. Am. Chem. Soc. 129 (2007) 6384; (b) F. Hajjaj, Z. S. Yoon, M. -C. Yoon, J. Park, A. Satake, D. Kim, Y. Kobuke, J. Am. Chem. Soc. 128 (2006) 4612.

10. (a) S. K. Mondal, S. Ghosh, K. Sahu, U. Mandal, K. Bhattacharyya, J. Chem. Phys. 125 (2006) 224710; (b) D. Cringus, A. Bakulin, J. Lindner, P. Vöhringer, M. S. Pshenichnikov, D. A. Wiersma, J. Phys. Chem. B 111 (2007) 14193.

11. M. Takahashi, Y. Suzuki, Y. Ichihashi, M. Yamashita, H. Kawai, Tetrahedron Lett. 48 (2007) 357.

12. B. Valeur, Molecular Fluorescence Principles and Applications, Wiley-VCH, Weinheim, New York, Chichester, Brisbane, Singapore, Toronto, 2002.

13. K. Tamao, S. Komada, I. Nakajima, M. Kumada, A. Minato, K. Suzuki, Tetrahedron 38 (1982) 3347.

14. F. Effenberger, S. Heid, R. Merkle, P. Zimmermann, Synthesis (1995) 1115. 
15. T. Yamato, N. Sakaue, N. Shinoda, K. Matsuo, J. Chem. Soc., Perkin Trans. 1 (1997) 1193. 


\section{Schemes}

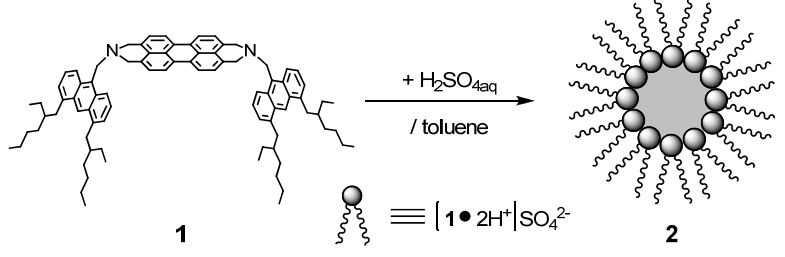

Scheme 1. Schematic representation of the reverse micelle formation.

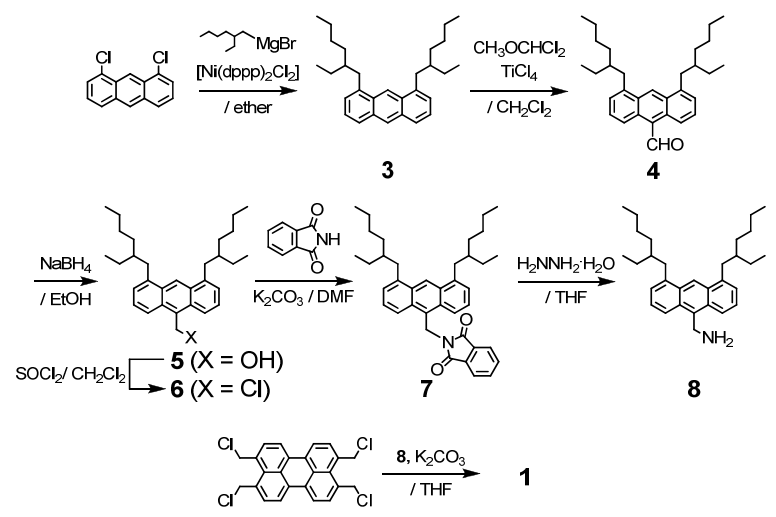

Scheme 2. Preparation of $\mathbf{1}$. 


\section{Figures}
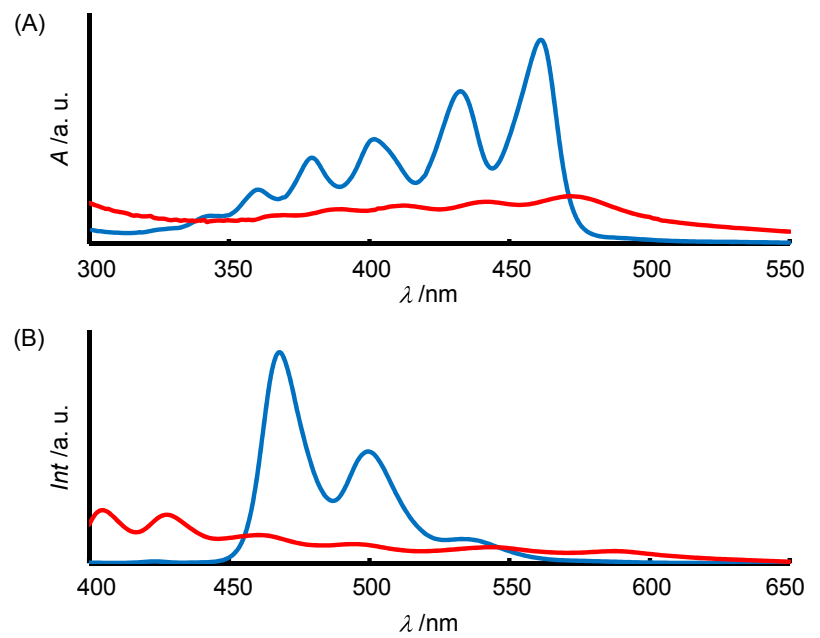

Fig. 1. (A) Absorption spectra of 1 (blue solid line; $c 10.0 \mu \mathrm{M}$ ) and 2 (red solid line; $c 10.0 \mu \mathrm{M}$ ) in toluene. (B) Fluorescence emission spectra $\left(\lambda_{\mathrm{ex}}=378 \mathrm{~nm}\right.$ ) of $\mathbf{1}$ (blue solid line; $c 0.10 \mu \mathrm{M}$ ) and $\mathbf{2}$ (red solid line; $c 10.0 \mu \mathrm{M})$ in toluene.

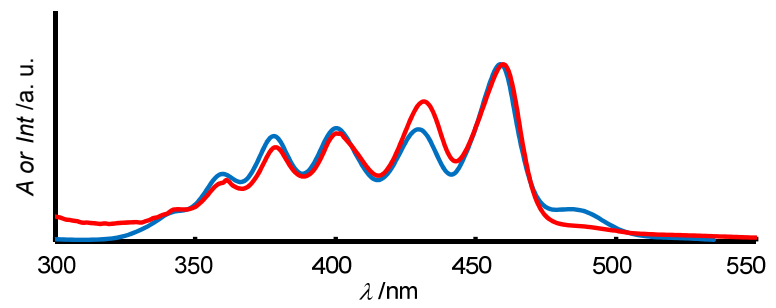

Fig. 2. Superposition of the absorption (red solid line; $c 10.0 \mu \mathrm{M}$ ) and excitation (blue solid line; $\lambda_{\text {em }}$ $=550 \mathrm{~nm}, c 0.1 \mu \mathrm{M})$ spectra of 1 in toluene normalized at $461 \mathrm{~nm}$. 

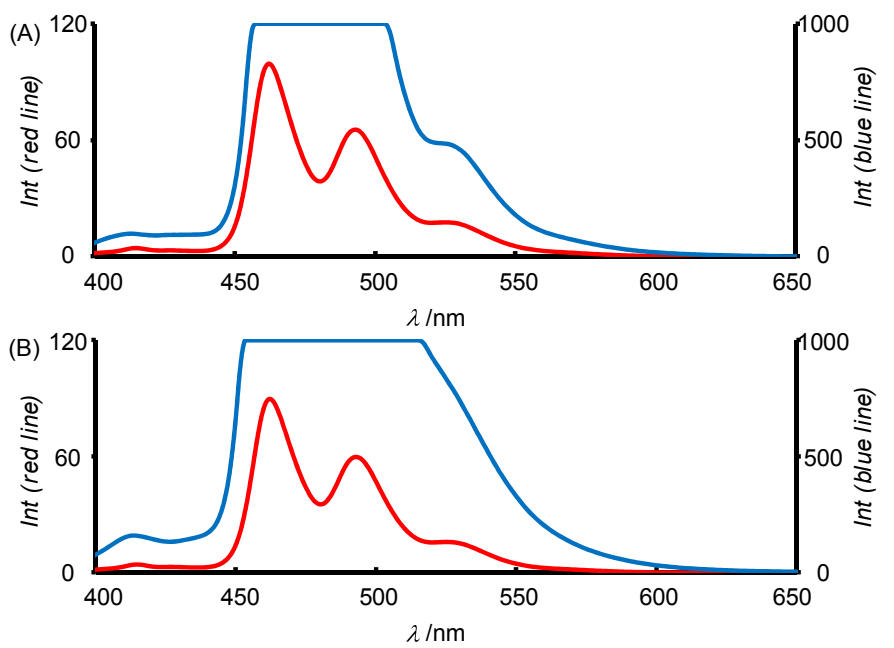

Fig. 3. (A) Fluorescence emission spectra $\left(\lambda_{\text {ex }}=378 \mathrm{~nm}\right)$ of mono-protonated 1 in ethanol at $10.0 \mu \mathrm{M}$ (blue solid line) and $0.10 \mu \mathrm{M}$ (red solid line). (B) Fluorescence emission spectra $\left(\lambda_{\mathrm{ex}}=378 \mathrm{~nm}\right)$ of diprotonated 1 in ethanol at $10.0 \mu \mathrm{M}$ (blue solid line) and $0.10 \mu \mathrm{M}$ (red solid line).

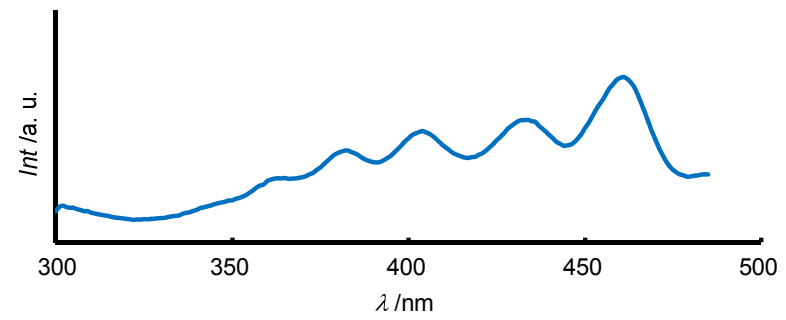

Fig. 4. Excitation spectrum of 2 in toluene $\left(\lambda_{\mathrm{em}}=500 \mathrm{~nm}, c 10.0 \mu \mathrm{M}\right)$.

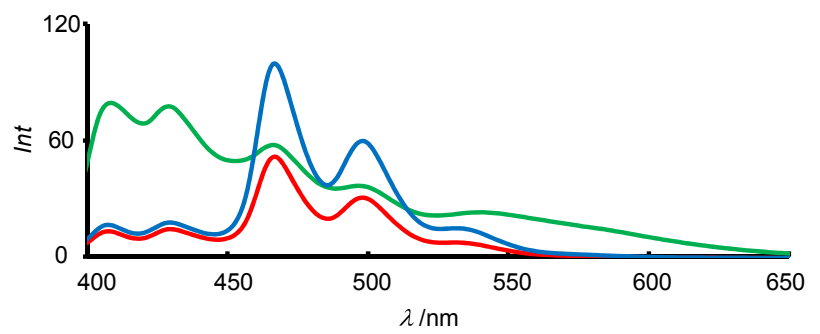

Fig. 5. Fluorescence emission spectra $\left(\lambda_{\mathrm{ex}}=378 \mathrm{~nm}\right.$ ) of di-protonated 1 in toluene at $10.0 \mu \mathrm{M}$ (green solid line; i.e. 2), $0.50 \mu \mathrm{M}$ (blue solid line) and $0.25 \mu \mathrm{M}$ (red solid line). 


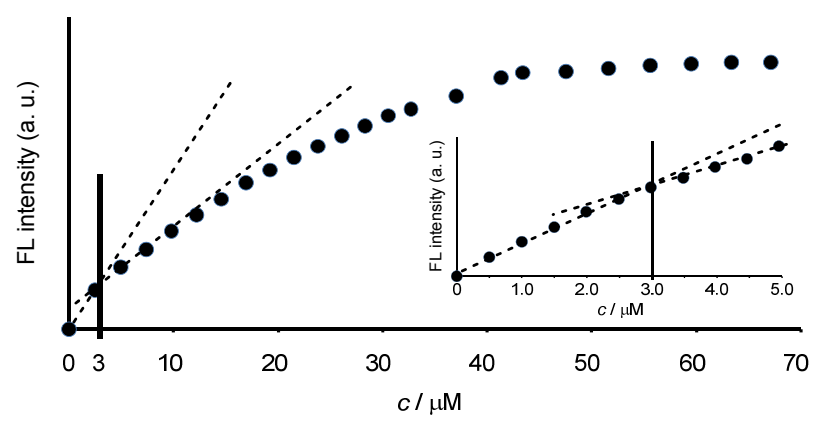

Fig. 6. Concentration dependence of fluorescence intensities of $\mathbf{2}\left(\left[\mathbf{1} \cdot 2 \mathrm{H}^{+}\right] \mathrm{SO}_{4}{ }^{2-}\right)$ in toluene. The inset shows an expansion of the region from 0 to $5 \mu \mathrm{M}$.

(A)

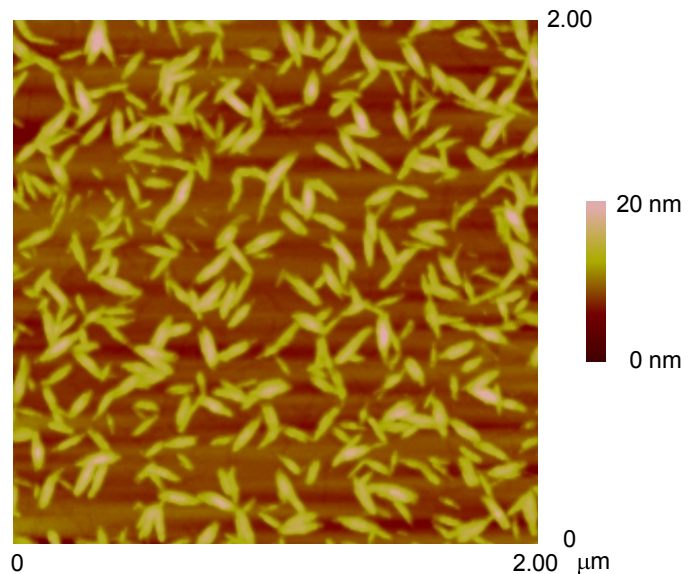

(B)

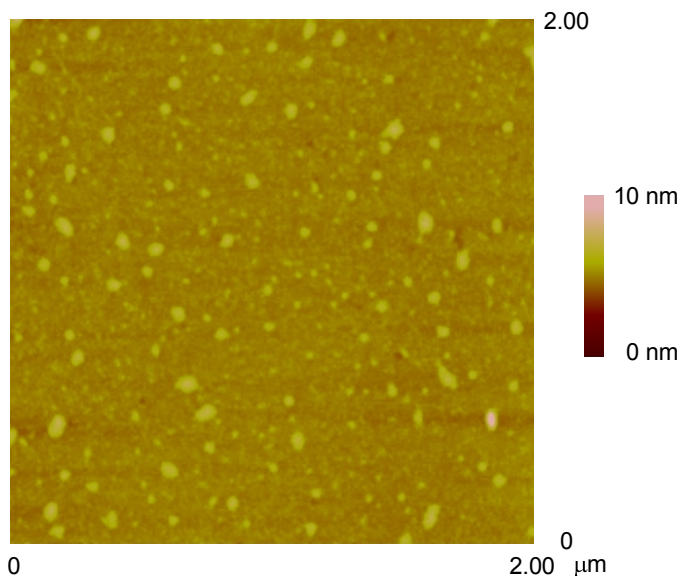

(C)

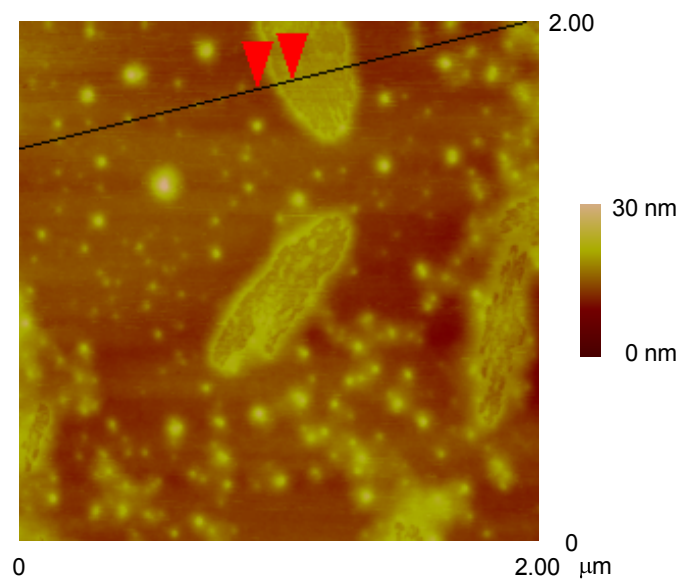

(D) $\mathrm{nm}$

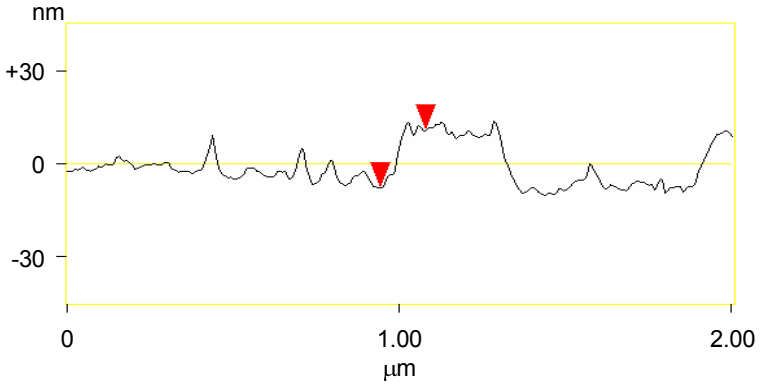

Fig. 7. (A) AFM images of drop-cast of toluene solutions of 1 at concentrations of $0.1 \mathrm{mM}$ and (B) $5.0 \mu \mathrm{M}$ on HOPG. (C) AFM image of drop-cast of 2 on HOPG (c $0.1 \mathrm{mM})$. (D) Height profile of 2 on a cross-section of the solid line in the AFM image. 


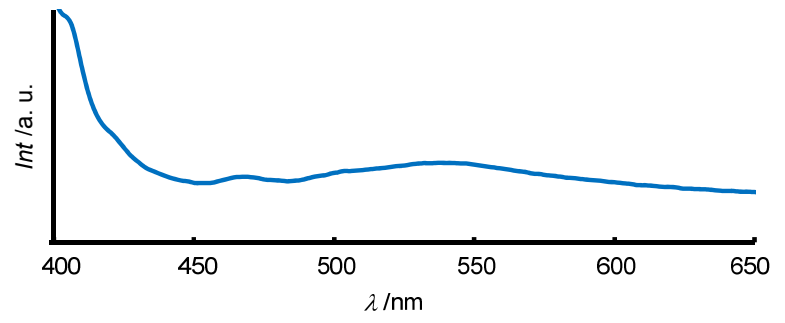

Fig. 8. Thin film fluorescence emission spectrum $\left(\lambda_{\mathrm{ex}}=378 \mathrm{~nm}\right)$ of 2 cast on a glass plate.
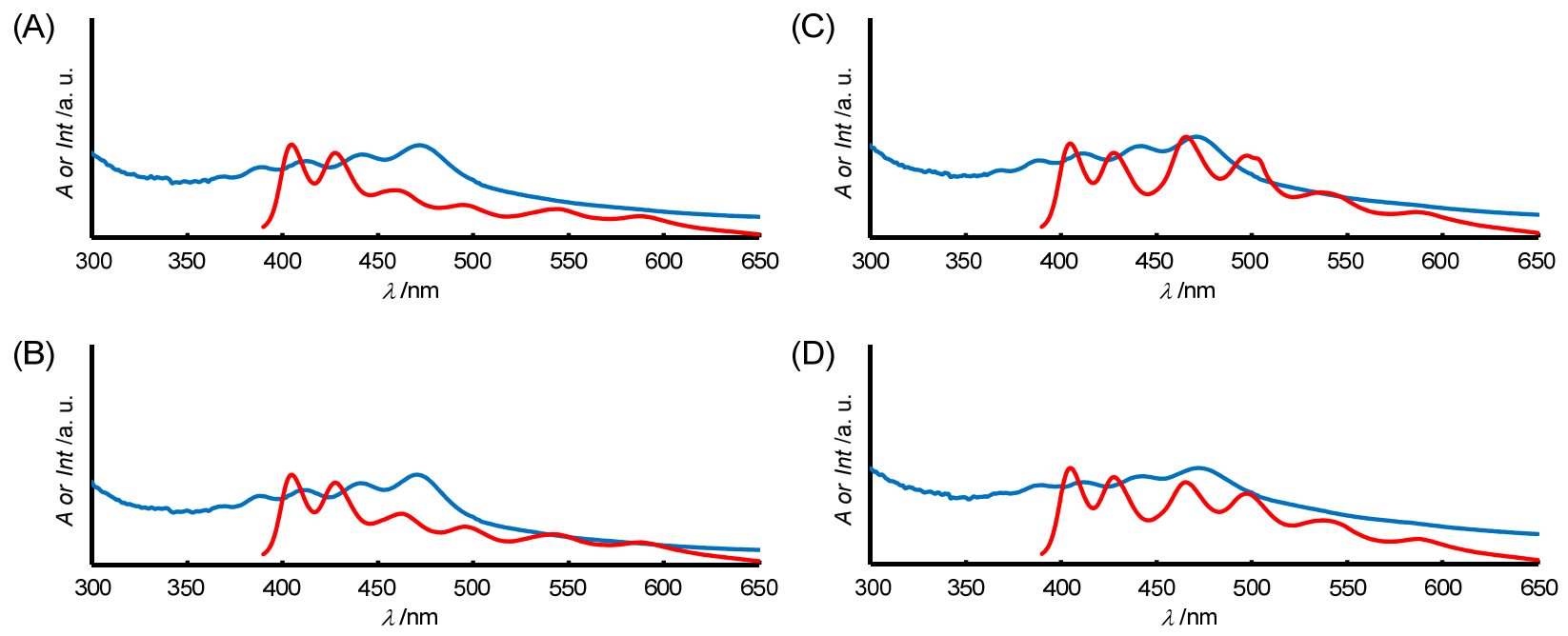

Fig. 9. (A) Absorption (blue solid line, $c 10.0 \mu \mathrm{M}$ ) and fluorescence emission spectra (red solid line, $\lambda_{\mathrm{ex}}=378 \mathrm{~nm}, c 10.0 \mu \mathrm{M}$ ) of 2 at $W_{0}=30$, (B) 50, (C) 100 and (D) 200 in toluene. 

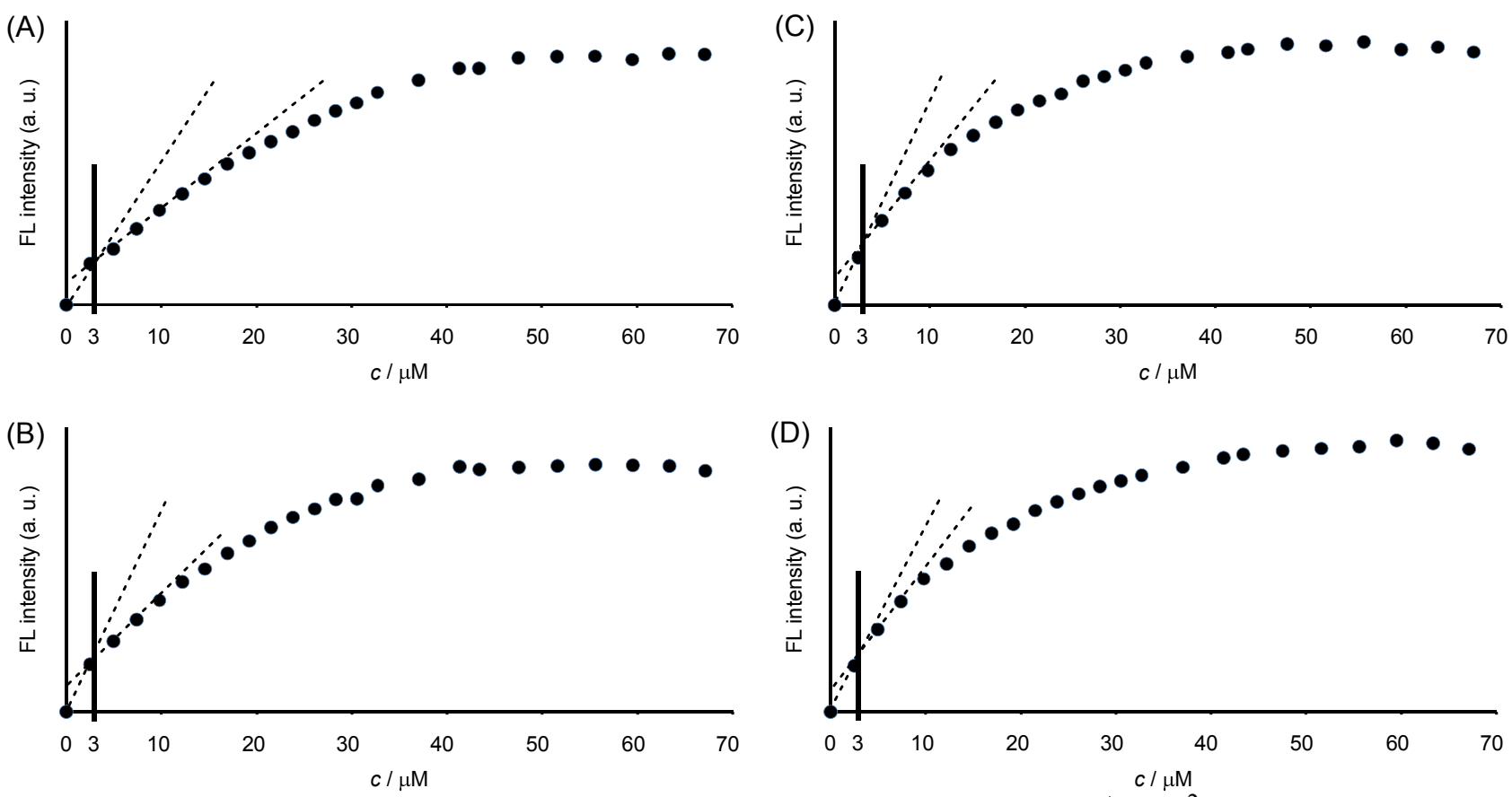

Fig. 10. (A) Concentration dependence of fluorescence intensities of $2\left(\left[1 \cdot 2 \mathrm{H}^{+}\right] \mathrm{SO}_{4}{ }^{2-}\right)$ at $W_{0}=30$, (B) 50 , (C) 100 and (D) 200 in toluene.

(A)

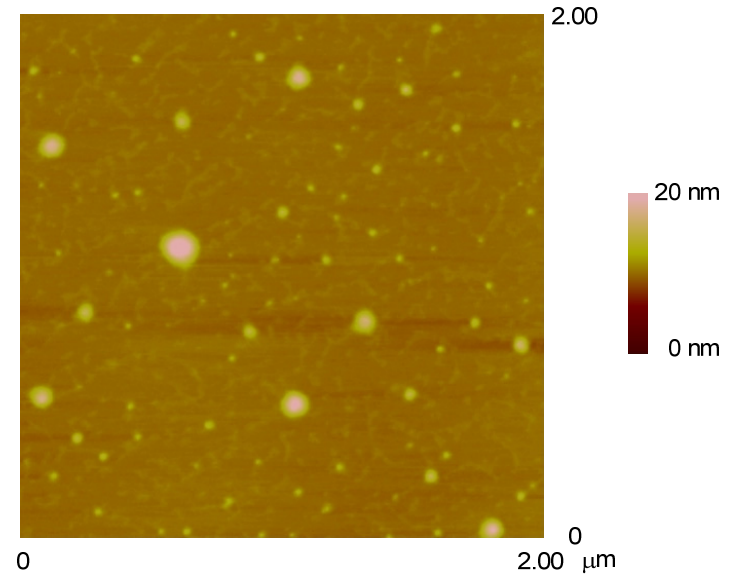

(B)

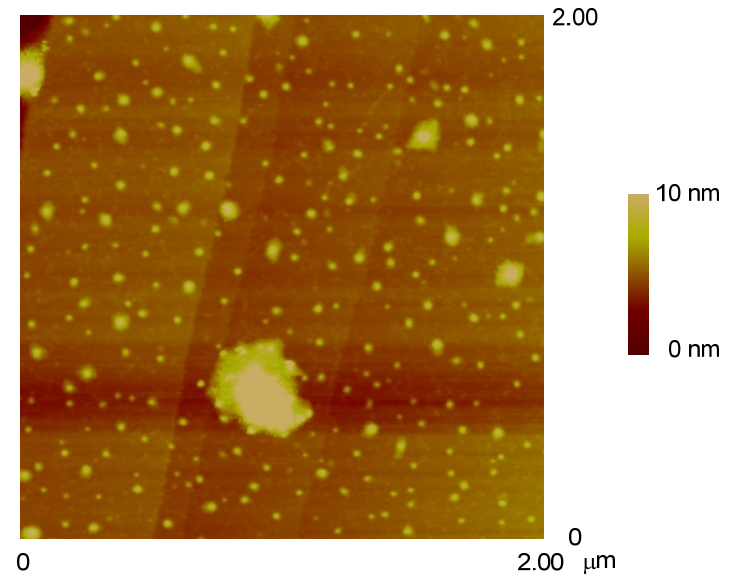

Fig. 11. (A) AFM images of drop-cast of toluene solutions of 2 at $W_{0}=30$ and (B) 50 on HOPG (c $0.1 \mathrm{mM})$. 